\title{
Red Raspberry (Rubus idaeus L.) Seed Oil: A Review
}

\author{
Audronè Ispiryan *, Jonas Viškelis (D) and Pranas Viškelis (D) \\ Lithuanian Research Centre for Agriculture and Forestry, Institute of Horticulture, Kauno str. 30, Kaunas District, \\ LT-54333 Babtai, Lithuania; jonas.viskelis@lammc.lt (J.V.); pranas.viskelis@lammc.lt (P.V.) \\ * Correspondence: audrone.ispiryan@lammc.lt
}

check for

updates

Citation: Ispiryan, A.; Viškelis, J.;

Viškelis, P. Red Raspberry

(Rubus idaeus L.) Seed Oil: A Review. Plants 2021, 10, 944. https://doi.org/ $10.3390 /$ plants 10050944

Academic Editors: Laima Česonienè, Othmane Merah and Abdelali Hannoufa

Received: 31 March 2021

Accepted: 3 May 2021

Published: 9 May 2021

Publisher's Note: MDPI stays neutral with regard to jurisdictional claims in published maps and institutional affiliations.

\begin{abstract}
Raspberry (Rubus idaeus L.) seed oil (RSO) is considered as a source of high value bioactive compounds as fatty acids, tocopherols, tocotrienols, carotenoids, flavonoids, phytosterols, antioxidants, monoterpenes and many other chemical constituents. These compounds are appreciated as a source of nutrition for humans, as additives in cosmetic production, has immense therapeutic potential. Raspberry seed oil exerts many pharmacological effects included antimicrobial, antioxidant, anti-inflammatory activity and many other effects. The various databases like PubMed and Science Direct were used to identify, analyze and summarize the research literature on raspberries. This review will highlight recent developments of the chemical constituents and nutraceutical and cosmetical effects of RSO. Practical application: analyzed recent researches and international patents containing raspberry seed oil can help practitioners of various industries create new high-value products.
\end{abstract}

Keywords: bioactive compounds; red raspberry; nutritional value; seed oil

\section{Introduction}

Recently has been observed a considerable openness and greater attention of researchers concerning the characterization of essential oils and secondary metabolites on known and lesser known plants which have highlighted how natural resources on this particular issue can still provide new scientific data scientific data which can be useful for human health [1,2]. Berries are a valuable source of a wide range of secondary metabolites, which can be used in pharmaceutical, agronomic and food industries [3-6].

In 2019, world production of raspberries was $822.49 \mathrm{~K}$ metric tons (mt), with Russia as the leading producer, supplying $22.0 \%$ of the world total. Other major producers were Mexico (16.3\%), Serbia (15.2\%), United States (13\%) and Poland (9.6\%) [7]. Most of raspberries are used for processing juices, jams, wine, etc. [4]. During the processing a large amount of berry by-products (pomace, seeds, etc.) are produced. Raspberry seeds are considered as by-product or waste [8]. Oil from raspberries seeds is receiving increasing attention among scientists, farmers, processors and consumers. This kind of berry oils often have a unique fatty acid profiles and has interesting other minor bioactive components that are in demand on the market [9].

Furthermore, raspberry seed oil (RSO) production provides the use of a renewable resource, adding value to agricultural products and improving the environment. Raspberry seeds contain up to $12.2 \%$ protein and has $11-23 \%$ oil. These oils have unique characteristics that makes interest to the cosmetics and medical industries [10]. The fruit and berry oils are characterized by gentle processing (no refining, cold pressing, etc.), unique aroma and health-promoting attributes, low production yield and high price [11].

Food industry is interested in creating more added value products through the applications of by-products [12]. Berry seed oils are often considered to be specialty oils with unique bioactive components [13]. These kinds of oils also have the most valuable plant fats [14]. Due to the various bioactive compounds, they can be included in functional foods [15], are appreciated as a diet component and preventing the development of various diseases [16]. 
The main aim of the work was to analyze the quantitative and qualitative characteristics of raspberry seeds oil. This review also proposes an overview of the possible RSO processing technologies and quality factors, pros and cons, significance of RSO for human health, nutrition and cosmetical value. Starting from this, an analysis of the most recent international patents related to RSO was carried out, in order to provide farmers, company managers, customers and other stakeholders an insight into the most suitable solution for the economic and environmental sustainability of the raspberry seeds oil in management chain.

\section{Raspberry Seeds Oil Processing Technologies and Quality Factors}

The quality of fruit seed oil highly depends on fruit genotype, growing region and conditions, seed pretreatment, drying parameters and oil extraction techniques. These factors significantly affect the extracted oil yield, it's bioactive compounds, antioxidant activity and oxidative stability [17].

The bioactive compounds of by-products can be extracted with Soxhlet extraction, hydro-distillation, maceration, cold-pressing and supercritical fluid extraction (SFE). SFE utilizes solvents (such as carbon dioxide) in its supercritical state, in which the solvent acts simultaneously as a liquid and as a gas, resulting in a more efficient extraction process [18].

Cold-pressing and SFE are the green methods for the extraction of valuable compounds from berry seeds, it does not use hazardous organic solvents. The only drawback of these green methods is that higher extraction yields are obtained with solvent extraction than SFE [19]. The advantages of working with SFE and cold-pressing are reduced solvent use, lower energy consumption, shorter extraction time and better quality [20]. There is still a need to utilize more novel and green techniques to the waste materials to achieve higher biologically active compounds retrieval rates.

\section{Physico-Chemical Characterization}

Raspberry seed oil is slightly cloudy, yellowish in color. This yellowish tinge to the oils is given by carotenoids. A yellowish tint is desirable because it gives the oil the characteristic butter-like appearance specifically to the oil without the addition of conventional dyes that are often used in the food industry [21].

Oil yield from the seeds is 10-23\% [6,16]. Raspberry seed oil has a high content of $n-6$ and $n-3$ essential fatty acids and is an important qualitative characteristic of an oil. The acidic value of raspberry seed oil is ranging from 17.18 to $18.74 \mathrm{mg} \mathrm{KOH} \mathrm{g}^{-1}$. The increasing acidity can be due to longer storage time of the berries [21].

The most unsaturated fatty acids in RSE are linoleic acid, a-linolenic acid and oleic acid. RSE if a good nutrient due to high content $(78.9-85.5 \%)$ of polyunsaturated fatty acids and phytosterols $\left(5384.1 \mathrm{\mu g} \mathrm{g}^{-1}\right)[6,16]$.

Fatty acids are vital components of human diet and are required by cells of the body in the form of phospholipids for structural membrane integrity [22]. The content of polyunsaturated fatty acids in red raspberry seed oil was reported as of $85 \%$, of which (as percentage of total fatty acids) had $54 \%$ of linoleic acid and $32 \%$ of $\alpha$-linolenic acid.

In RSO there are also polyphenol compounds $\left(2.65 \mathrm{mg} 100 \mathrm{~g}^{-1}\right.$ ), phytosterols $\left(5.38 \mathrm{mg} \mathrm{g}^{-1}\right)$, including campesterol, stigmasterol, sitosterol, avenasterol, cytrostadienol; and carotenoids, including zeaxanthin, $\beta$-carotene, lutein and cryptoxanthin [23]. RSO also contains large amounts of vitamin E (301.9 mg $\left.100 \mathrm{~g}^{-1}\right)$; tocopherols (295.19 mg $100 \mathrm{~g}^{-1}$ ), including $\alpha$-tocopherol $\left(71 \mathrm{mg} 100 \mathrm{~g}^{-1}\right), \gamma$-tocopherol $\left(272 \mathrm{mg} 100 \mathrm{~g}^{-1}\right), \Delta$-tocopherol

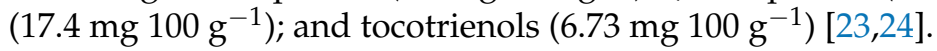

Antioxidants are another very important dietary components, including vitamin E, phenolic compounds and tocopherols, which protects the body from free radical damage among other functions. These components are prevalent at significant levels in raspberry seed oils $[25,26]$.

Summarizing the research literature, RSO is a unique source of bioactive phytochemicals containing high levels of antioxidant components. Oil yield from the raspberry seed is 
not high (from 10 to $20 \%$ ). RSO well-known for its components: fatty acids, vitamin E so appreciated in cosmetics and pharmaceuticals industries. RSO is also known for its high antioxidant capacity and exhibits anti-inflammatory, anti-mutagenic and antimicrobial properties [27]. RSO is also used in cosmetics as an efficient moisturizer and emollient which helps to reduce the oxidative stress in skin, is used in cosmetic emulsions for UV protection [6].

\section{Significance of RSO for Human Health}

\subsection{Nutritional Value}

Safe and natural medicinal foods are gaining significance in mainstream healthcare [28-30]. An increasing number of studies in recent years have shown the health benefits of using raspberry seed oil as a dietary supplement in the global scientific literature. The main ingredients of RSO are essential fatty acids (C18:2 n-6, linoleic and C18:3, $n$-3, $\alpha$-linolenic acid) with a 1.8-fold prevalence of linoleic acid [26,31,32]. The human organism cannot synthesize them, but they are required for a good health [33]. The ratio of omega- 6 to omega-3 fatty acids in the RSO is very favorable for nutrition (approximately 1.4:1).

According to the European Scientific Committee on Food (ESCF), 2\% of the total daily energy intake should be derived from omega- 6 and $0.5 \%$ from omega- 3 polyunsaturated fatty acids [34], which corresponds to a daily intake of approx. $6 \mathrm{~g}$ per day for woman (5 $\mathrm{g}$ of omega- 6 and $1 \mathrm{~g}$ of omega-3) and $8 \mathrm{~g}$ per day for men (6.4 g of omega-6 and $1.6 \mathrm{~g}$ of omega-3) [35]. A diet rich in fatty acids and low in dietary fiber increases the risk of obesity, type 2 diabetes, cardiovascular and many other diseases [36]. Meanwhile the World Health Organization (WHO) recommends a $2.5-9 \%$ of omega-6 intake and $0.5-2 \%$ of omega-3 fatty acid intake of daily energy. These differences between ESCF and WHO recommendations occurs due to different nutritional goals, where ESCF recommendation is based on the amounts necessary to correct a clinically overt deficiency, WHO recommendation is based on considerations of cardiovascular health and neurodevelopment [37]. Due to the presence of fatty acids in raspberry seed oil, it can be used as a dietary supplement and has a positive effect against many diseases [38].

The RSO is also rich in tocopherols-3.3-3.5 $\mathrm{mg} \mathrm{g}^{-1}$ (compounds with vitamin E activity). A health claim has also been confirmed for this vitamin: "Vitamin E helps protect cells from oxidative damage". The recommended daily allowance for vitamin $\mathrm{E}$ is from $4 \mathrm{mg}$ for children to $15 \mathrm{mg}$ for adults. This means that $3-5 \mathrm{~g}$ of oil per day fully supplies the human body with vitamin E, which helps to protect cells from the damage caused by free radicals, boosts immune system, helps to keep blood from clotting with blood vessels, might help to prevent Alzheimer's disease, maintain brain health and carry out many other important functions [39-41].

\subsection{Cosmetical Value}

RSO is gaining increasing attention by cosmetics industry. It is used as an ingredient in body and face moisturizers because of its high concentrations of Vitamins A and E. These vitamins are essential for the maintenance and repair of skin cells. The oil works by creating a lipid barrier that stops skin from losing natural moisture. Retaining moisture helps to keep skin cells looking young and full. Raspberry oil can be used as a base for makeup applications. It adds adding hydration, sun protection and nourishing vitamins.

The primary factors that contribute to premature aging of the skin include UV from the sun, illness, smoking and drinking. Raspberry seed oil is packed with carotenoids-a plant derived source of Vitamins A and E. These compounds are widely used in many anti-aging skin care products to help promote youthful skin [25,42]. Vitamin A is a popular antioxidant and ingredient in anti-aging skincare products because it adds moisture, reduces the appearance of wrinkles and smooths skin texture. Vitamin E is another highly praised antioxidant in the anti-aging industry. It helps to protect cells from oxidative damage and assists with maintaining collagen structure [43]. 
Research has demonstrated that people with higher levels of antioxidants have fewer and less pronounced wrinkles than those with low levels. This oil is of particular interest to medical experts (and us natural product enthusiasts) because it naturally contains sun protective compounds in addition to its beneficial antioxidants [42].

Raspberry seed oil is a very lightweight gentle moisturizing solution. Unlike other emollients, it does not clog pores and encourages natural water retention in the cells. This keeps them looking full, giving a more youthful appearance and reduces the appearance of fine lines and wrinkles. RSO is also noncomedogenic, meaning it will not clog your pores. Use it to moisture your face without blocking your pores [44]. Additionally, raspberry oil's sun protective qualities offer added benefit to people looking for a mild, non-irritating moisturizer with a sun protection factor (SPF) $[45,46]$.

Raspberries contain antimicrobial properties that are powerful enough to stop the growth of harmful bacteria such strains such as salmonella and E. coli (Escherichia coli). Although there is no substitute for proper oral hygiene, raspberry seed oil might be beneficial in destroying harmful bacteria found in the mouth. It might also assist in healing painful and inflamed gums that have been irritated by the plaque deposits $[47,48]$. RSO can also moisturize and soften the skin as well as reduce skin irritations such as itching, swelling and redness [49,50].

Oomah et al. [6] reports that RSO can be used as a broad-spectrum UV protectant and provide protection against both UV-A and UV-B. However, not many other SPF tests on raspberry seed oil have been made, but the interest in RSO has accelerated [51]. Meanwhile, a very recent research by Ácsová et al. [49] in 2021 has revealed that the oil may not be as effective as concluded in Oomah et al. [6] research. In the latest study SPF values of the RSO in vitro was 0.4 , in vivo 2.6 , and it is significantly lower than the values reported in the controversial studies. Ácsová et al. [49] showed that the overestimated SPF values of RSO was determined by authors who did not strictly followed Mansur's original methodology.

It is sure that RSO can make a great addition to an organic product because of its abundant amount of antioxidants, including Vitamin E, which helps to block free radicals. Not to mention plenty of the incredibly beneficial micronutrients called polyphenols. Therefore, with the growing demand for natural sunscreen products, it would be useful to conduct in-depth research to substantiate or refute one or another author.

\section{Patents on RSO}

When an inventor finds a solution to a particular problem, one needs to make sure the solution is new. In addition, the description of the invention must indicate and compare solutions to similar problems with the patented solution. Determining the state of the art makes it possible to see which technical field is already protected by patents and to predict the direction in which new solutions can be sought. The search for raspberry seeds oil novelty and technical level (also called patent search) was carried out in publicly available free international patent databases containing data on issued patents [52]. Table 1 illustrates an updated report on application of RSO. 
Table 1. Updated list on patents of raspberry seeds oil.

\begin{tabular}{|c|c|c|c|}
\hline Patentscope & Patent's Title & Publication Number & Publication Year and Office \\
\hline \multirow{9}{*}{ 1. Technologies } & $\begin{array}{l}\text { 1.1. Dimethicone copolyol raspberriate as a } \\
\text { delivery system for natural antioxidants; }\end{array}$ & 6630180 & 2003, USA \\
\hline & $\begin{array}{l}\text { 1.2. Raspberry amido amines and betaines as a } \\
\text { delivery system for natural antioxidants; }\end{array}$ & 7078545 & 2006, USA \\
\hline & $\begin{array}{l}\text { 1.3. Synergistic super potent antioxidant cold } \\
\text { pressed botanic oil blends; }\end{array}$ & 20070243310 & 2007, USA \\
\hline & $\begin{array}{l}\text { 1.4. Method of making edible oil with } \\
\text { unsaturated fatty acid content of more than } 90 \% \\
\text { by extracting roasted bramble seed with hexane } \\
\text { purpose; }\end{array}$ & 1020070080027 & 2007, Korea \\
\hline & 1.5. Immune enhancement by seed oil; & 20090324759 & 2009, USA \\
\hline & $\begin{array}{l}\text { 1.6. Ultrasonic wave auxiliary extraction method } \\
\text { for extracting raspberry seed oil; }\end{array}$ & 102864012 & 2013, China \\
\hline & $\begin{array}{l}\text { 1.7. Composite extract of black raspberry oil, } \\
\text { raspberry oil and mulberry oil; }\end{array}$ & WO/2015/137633 & 2015, Korea \\
\hline & $\begin{array}{l}\text { 1.8. Preparation method of raspberry seed oil } \\
\text { and product prepared therefrom; }\end{array}$ & 106947583 & 2017, China \\
\hline & 1.9. Raspberry seed oil extraction technology; & 109022136 & 2018, China \\
\hline \multirow{8}{*}{$\begin{array}{l}\text { 2. Pharmaceutical } \\
\text { products }\end{array}$} & $\begin{array}{l}\text { 2.1. Raspberry seed oil compsns-with } \\
\text { antiinflammatory activity, for cosmetic and } \\
\text { pharmaceutical use; }\end{array}$ & 2255055 & 1975, France \\
\hline & 2.2. Topical steroid spray with botanic seed oils; & 20090304603 & 2009, USA \\
\hline & 2.3. Berry oils and products; & 20110280971 & 2011, USA \\
\hline & $\begin{array}{l}\text { 2.4. Raspberry seed oil soft capsule and } \\
\text { preparation method thereof; }\end{array}$ & 102687861 & 2012, China \\
\hline & 2.5. Dietary supplement to treat dry eyes; & 2013101038 & 2013, Australia \\
\hline & $\begin{array}{l}\text { 2.6. Traditional chinese medicine essential oil for } \\
\text { relieving fatigue and preparation method of } \\
\text { traditional chinese medicine essential oil; }\end{array}$ & 104800783 & 2015, China \\
\hline & $\begin{array}{l}\text { 2.7. Complex extract of black raspberry oil, } \\
\text { raspberry oil and mulberry oil; }\end{array}$ & 1020160047055 & 2016, Korea \\
\hline & $\begin{array}{l}\text { 2.8. Soft-capsules containing sea buckthorn } \\
\text { seed oil; }\end{array}$ & 108497499 & 2018, China \\
\hline \multirow{8}{*}{$\begin{array}{l}\text { 3. Cosmetic } \\
\text { products }\end{array}$} & 3.1. Cleansing sheet; & 2003226637 & 2003, Japan \\
\hline & $\begin{array}{l}\text { 3.2. Compositions, to reinforce and restore } \\
\text { functional barrier of skin and to control } \\
\text { inflammation, comprises insaponifiable fraction } \\
\text { of rape oil; }\end{array}$ & 2912652 & 2009, France \\
\hline & $\begin{array}{l}\text { 3.3. Skin care compositions with botanic } \\
\text { seed oils; }\end{array}$ & 20090123578 & 2011, USA \\
\hline & $\begin{array}{l}\text { 3.4. Natural korean herb cosmetics capable of } \\
\text { being applied to sensitive skin; }\end{array}$ & 101262557 & 2013, Korea \\
\hline & 3.5. Anti-aging cosmetic composition; & WO/2013/066623 & 2013, USA \\
\hline & 3.6. Cream pack containing raspberry; & 106955249 & 2017, China \\
\hline & 3.7. Eye cream containing raspberry; & 107041862 & 2017, China \\
\hline & $\begin{array}{l}\text { 3.8. Healthcare chest-enlarging weight-losing } \\
\text { molding multifunctional massage oil for external } \\
\text { use and preparation method thereof; }\end{array}$ & 106667859 & 2017, China \\
\hline
\end{tabular}


Table 1. Cont.

\begin{tabular}{|c|c|c|c|}
\hline Patentscope & Patent's Title & Publication Number & Publication Year and Office \\
\hline & $\begin{array}{l}\text { 3.9. Novel herbal sunscreen formulation and } \\
\text { method thereof; }\end{array}$ & 201611003234 & 2017, India \\
\hline & $\begin{array}{l}\text { 3.10. Anti-aging, soothing and moisturizing gel } \\
\text { and preparation method thereof; }\end{array}$ & 108852928 & 2018, China \\
\hline & $\begin{array}{l}\text { 3.11. Environmental-protection facial mask base } \\
\text { material and preparation method and } \\
\text { application thereof; }\end{array}$ & 108926504 & 2018, China \\
\hline & $\begin{array}{l}\text { 3.12. Anti-wrinkle oil-control acne-removing } \\
\text { repair mask and preparation method thereof; }\end{array}$ & 108904371 & 2018, China \\
\hline & $\begin{array}{l}\text { 3.13. Sun-protection lipstick and preparation } \\
\text { method thereof; }\end{array}$ & 111789782 & 2020, China \\
\hline \multirow{7}{*}{$\begin{array}{l}\text { 4. Bathing } \\
\text { products }\end{array}$} & $\begin{array}{l}\text { 4.1. Dandruff treatment compositions with } \\
\text { anti-inflammatory agents including botanic } \\
\text { seed oils; }\end{array}$ & 20090317502 & 2009, USA \\
\hline & $\begin{array}{l}\text { 4.2. Raspberry soap composition having } \\
\text { antibiotic and antioxidant function by } \\
\text { comprising raspberry seed oil and } \\
\text { raspberry wine; }\end{array}$ & 1020120052467 & 2012, Korea \\
\hline & $\begin{array}{l}\text { 4.3. Cosmetic or bathing product containing rubi } \\
\text { fructus seed extract and antioxidative } \\
\text { ingredients purpose; }\end{array}$ & 1020110129606 & 2012, Korea \\
\hline & $\begin{array}{l}\text { 4.4. Silicon oil free shampoo capable of } \\
\text { preventing alopecia and preparation method } \\
\text { of shampoo; }\end{array}$ & 106473994 & 2017, China \\
\hline & 4.5. Anti-soap formulation; & 20190133921 & 2019, USA \\
\hline & 4.6. Preparation method of de-oil shampoo; & 109925228 & 2019, China \\
\hline & 4.7. Oil-control shampoo; & 109925231 & 2019, China \\
\hline \multirow{2}{*}{ 5. Oral care } & $\begin{array}{l}\text { 5.1. Novel composition for herbal mouthwash } \\
\text { and process for the preparation of the same; }\end{array}$ & 1376/DEL/2012 & 2014, India \\
\hline & $\begin{array}{l}\text { 5.2. Whitening and anti-sensitivity aloe gel and } \\
\text { preparation method thereof; }\end{array}$ & 108714130 & 2018, China \\
\hline 6. Food & $\begin{array}{l}\text { 6.1. fruit products containing omega-3 } \\
\text { fatty acids. }\end{array}$ & WO/2010/011712 & 2010, USA \\
\hline
\end{tabular}

The oldest registered patent relating to raspberry seed oil is in 1975 in France. The invention relates to cosmetic or pharmaceutical compositions, more particularly products for dental care, skin creams and lotions, shampoos and make-up. One frequently meets in cosmetology phenomena of inflammation, such as that of the gums, called gingivitis, that of the epidermis, called erythema, eczemas or other skin lesions. The origin of these inflammations can be very varied: biological deficiency, allergy, the effect of the sun's rays and often the ingredients of the beauty products themselves.

Substances with an anti-inflammatory effect are well known, such as cortisones, phenylbutazone, salicylates, indomethacin, anthranilic acid derivatives, proteases, which, besides their effectiveness, also cause side effects. The subject of the invention is the incorporation into cosmetic or pharmaceutical products of a new anti-inflammatory substance of natural origin, pressure oil or raspberry seed extraction oil, hereinafter called raspberry seed oil. Raspberry seeds, capable of preventing or suppressing inflammatory phenomena, for example of the gums or the epidermis.

The patent authors state that RSO, expressed or extracted from raspberry seeds have anti-inflammatory activity and are useful in anti-sunburn preparations, dental prepara- 
tions, mouth-washes, after shaving preparations, antiperspirants, shampoos, lipsticks, etc. RSO as a dietary supplement has multiple functions of lowering blood lipid, cholesterol and blood pressure, resisting thrombus and arteriosclerosis, preventing cardiovascular disease, enhancing memory and preventing Alzheimer's disease and cancer and has a high nutritional value and health care function. The authors also note that changing waste (raspberry seeds) into high value products having great significance for the development of the red raspberry industry and the comprehensive utilization of byproducts.

The countries that have registered the most patents are China (17 patents) and USA (11 patents). It can be concluded that the fatty acids, vitamins A and E help in resorting skin elasticity, skin hydration, thus, finding its implication as anti-aging and in various other skin diseases as a result, oil has found a large niche in the cosmetics industry and is also significant in the pharmaceutical industry (Figure 1).

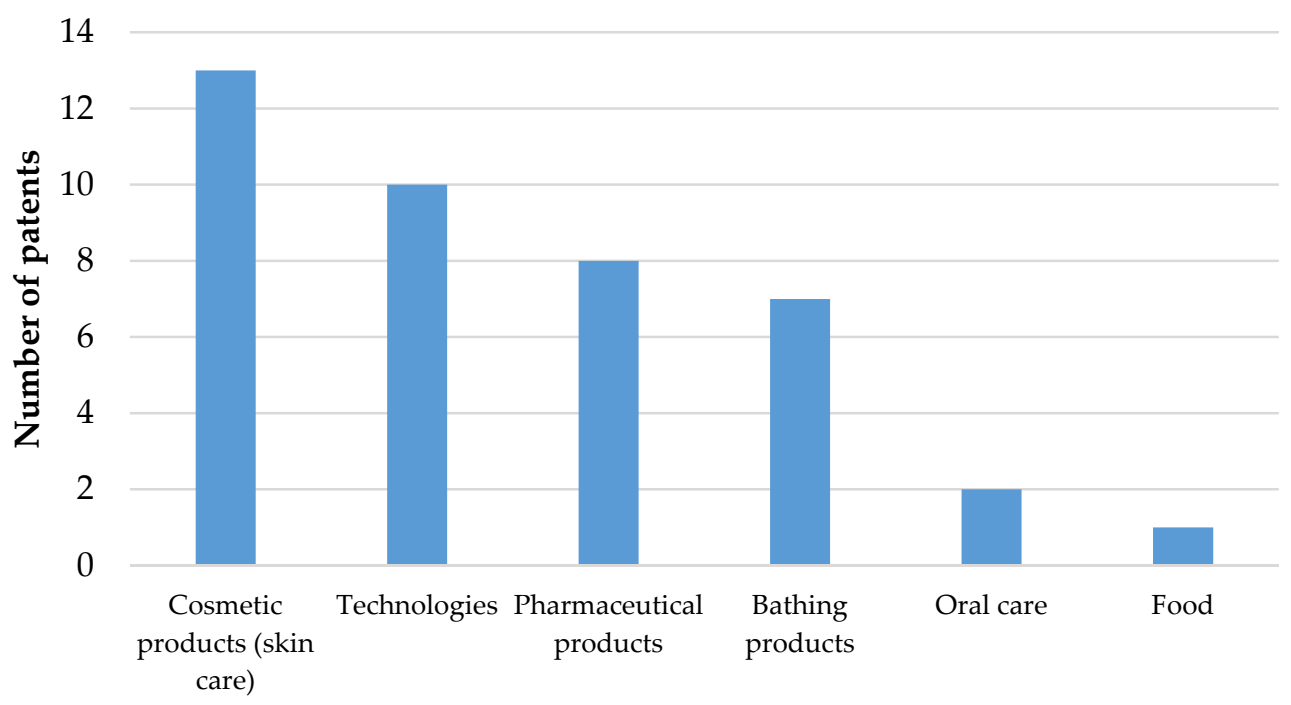

Figure 1. International patents relating to raspberry seeds oil.

\section{Conclusions}

Raspberry seeds oil can be used in food, pharmaceutical, cosmetic and chemical industries, it has a medicinal and therapeutic value. The so-called green oil production methods (SFE and cold-pressed techniques) ensure the sustainable realization of high-value products that meet the needs of the consumer of this time, the development of zero-waste technology in the circular economy. RSO has high content of polyunsaturated fatty acids, tocopherols, polyphenols and fatty acids which help in the prevention and treatment of various disorders. The benefits of RSO for external use have been extensively studied, products are widespread and recognized by consumers in the cosmetics industry. However, there is a lack of information on RSO as food consumption.

To conclude this review, RSO represents a potential source of natural ingredients for food, cosmetics and pharmaceutical industries. Due to the high nutritional value of raspberry by-products, it can be exploited as food additives or supplements providing the high valuable products which may be economically attractive for consumers. Both internal and external consumption of raspberry seed oil have a significant impact on human health, but there is a lack of data on internal consumption dosing and treatment for the prevention of specific diseases.

In the future, it would be useful to examine the influence of the oil on the internal consumption. It would be appropriate and interesting to confirm or deny the properties of the oil for sun protection as well. There is also a lack of information on the impact of different oil extraction technologies on its yield and quality, which would be valuable in practice for business representatives. 
Author Contributions: Conceptualization, writing—original draft preparation, A.I.; writing—review and editing, J.V.; supervision, P.V. All authors have read and agreed to the published version of the manuscript.

Funding: This study was financed by the Lithuanian Research Centre for Agriculture and Forestry and attributed to the long-term research program, "Horticulture: agrobiological foundations and technologies".

Institutional Review Board Statement: Not applicable.

Informed Consent Statement: Not applicable.

Data Availability Statement: Not applicable.

Conflicts of Interest: The authors declare no conflict of interest.

\section{References}

1. Viskelis, P.; Rubinskiene, M.; Bobinaite, R.; Dambrauskiene, E. Bioactive compounds and antioxidant activity of small fruits in Lithuania. J. Food Agric. Environ. 2010, 8, 259-263.

2. Perrino, E.; Valerio, F.; Gannouchi, A.; Trani, A.; Mezzapesa, G. Ecological and Plant Community Implication on Essential Oils Composition in Useful Wild Officinal Species: A Pilot Case Study in Apulia (Italy). Plants 2021, 10, 574. [CrossRef] [PubMed]

3. Al-Snafi, A.E. Medicinal plants possessed anti-inflammatory antipyretic and analgesic activities (part 2)-plant based review. Sch. Acad. J. Pharm. 2016, 5, 142-158.

4. Bobinaitè, R.; Viskelis, P.; Bobinas, Č.; Mieželienè, A.; Alenčikienè, G.; Venskutonis, P.R. Raspberry marc extracts increase antioxidative potential, ellagic acid, ellagitannin and anthocyanin concentrations in fruit purees. LWT Food Sci. Technol. 2016, 66, 460-467. [CrossRef]

5. Sagar, N.A.; Pareek, S.; Sharma, S.; Yahia, E.M.; Lobo, M.G. Fruit and Vegetable Waste: Bioactive Compounds, Their Extraction, and Possible Utilization. Compr. Rev. Food Sci. Food Saf. 2018, 17, 512-531. [CrossRef] [PubMed]

6. Oomah, B.D.; Ladet, S.; Godfrey, D.V.; Liang, J.; Girard, B. Characteristics of raspberry (Rubus idaeus L.) seed oil. Food Chem. 2000, 69, 187-193. [CrossRef]

7. TRIDGE. Digital Platform that Combines Technology and Human Network to Connect Buyers and Suppliers Globally. Available online: https: / / www.tridge.com/products/raspberry (accessed on 26 April 2021).

8. Wadaa, S.; Reed, B.M. Standardizing germination protocols for diverse raspberry and blackberry species. Sci. Hort. 2011, 132, 42-49. [CrossRef]

9. Tosun, M.; Ercisli, S.; Karlidag, H.; Şengül, M. Characterization of Red Raspberry (Rubus idaeus L.) Genotypes for Their Physicochemical Properties. J. Food Sci. 2009, 74, C575-C579. [CrossRef] [PubMed]

10. Matthäus, B. Oil technology. In Technological Innovations in Major World Oil Crops; Gupta, S.K., Ed.; Springer: New York, NY, USA, 2012; Volume 2, pp. 23-82.

11. Ramadan, M.F. Fruit Oils: Chemistry and Functionality; Springer: Berlin/Heidelberg, Germany, $2019 ;$ p. 911.

12. Langelaan, H.C.; Pereira da Silva, F.; Thoden van Velzen, U.; Broeze, J.; Matser, A.M.; Vollebregt, M. Technology options for feeding 10 billion people. In Options for Sustainable Food Processing; IC STOA: Brussels, Belgium, 2013; p. 16.

13. Van Hoed, N.; De Clercq, V.; Echim, C.; Andjelkovic, M.; Leber, E.; Dewettinck, K.; Verhé, R. Berry seeds: A source of specialty oils with high content of bioactives and nutritional value. J. Food Lipids. 2009, 16, 33-49. [CrossRef]

14. Pieszka, M.; Migdał, W.; Gąsior, R.; Rudzińska, M.; Bederska-Łojewska, D.; Pieszka, M.; Szczurek, P. Native Oils from Apple, Blackcurrant, Raspberry, and Strawberry Seeds as a Source of Polyenoic Fatty Acids, Tocochromanols, and Phytosterols: A Health Implication. J. Chem. 2015, 2015, 1-8. [CrossRef]

15. Michalak, M.; Kiełtyka-Dadasiewicz, A. Nut Oils and their Dietetic and Cosmetic Significance: A Review. J. Oleo Sci. 2019, 68, 111-120.

16. Shahidi, F.; Shukla, V.K.S. Nontriacylglycerol constituents of fats, oils. Information 1996, 7, 1227-1232.

17. Kaseke, T.; Opara, U.L.; Fawole, O.A. Fatty acid composition, bioactive phytochemicals, antioxidant properties and oxidative stability of edible fruit seed oil: Effect of preharvest and processing factors. Heliyon 2020, 6, 04962. [CrossRef] [PubMed]

18. Gustinelli, G.; Eliasson, L.; Svelander, C.; Andlid, T.; Lundin, L.; Ahrné, L.; Alminger, M. Supercritical Fluid Extraction of Berry Seeds: Chemical Composition and Antioxidant Activity. J. Food Qual. 2018, 2018, 1-10. [CrossRef]

19. Sahena, F.; Zaidul, I.S.M.; Jinap, S.; Karim, A.A.; Abbas, K.A.; Norulaini, N.A.N.; Omar, A.K.M. Application of supercritical CO2 in lipid extraction-A review. J. Food Eng. 2009, 95, 240-253. [CrossRef]

20. Marić, B.; Pavlić, B.; Čolović, D.; Abramović, B.; Zeković, Z.; Bodroža-Solarov, M.; Ilić, N.; Teslić, N. Recovery of high-content $\omega-3$ fatty acid oil from raspberry (Rubus idaeus L.) seeds: Chemical composition and functional quality. LWT Food Sci. Technol. 2020, 130, 109627. [CrossRef]

21. Dimic, E.B.; Vujasinovic, V.B.; Radocaj, O.F.; Pastor, O.P. Characteristics of blackberry and raspberry seeds and oils. Acta Period. Technol. 2012, 43, 1-9. [CrossRef] 
22. Mildner-Szkudlarz, S.; Różańska, M.; Siger, A.; Kowalczewski, P.L.; Rudzińska, M. Changes in chemical composition and oxida-tive stability of cold-pressed oils obtained from by-product roasted berry seeds. LWT Food Sci. Technol. 2019, 111, 541-547. [CrossRef]

23. Šućurović, A.; Vukelić, N.; Ignjatović, L.; Brčeski, I.; Jovanović, D. Physical-chemical characteristics and oxidative stability of oil obtained from lyophilized raspberry seed. Eur. J. Lipid Sci. Technol. 2009, 111, 1133-1141.

24. Kamal-Eldin, A.; Appelqvist, L.- $\AA$. The chemistry and antioxidant properties of tocopherols and tocotrienols. Lipids 1996, 31, 671-701. [CrossRef]

25. Niculae, G.; Lacatusu, I.; Badea, N.; Stan, R.; Vasile, B.S.; Meghea, A. Rice bran and raspberry seed oil-based nanocarriers with self-antioxidative properties as safe photoprotective formulations. Photochem. Photobiol. Sci. 2014, 13, 703-716. [CrossRef] [PubMed]

26. Teng, H.; Lin, Q.; Li, K.; Yuan, B.; Song, H.; Peng, H.; Yi, L.; Wei, M.-C.; Yang, Y.-C.; Battino, M.; et al. Hepatoprotective effects of raspberry (Rubus coreanus Miq.) seed oil and its major constituents. Food Chem. Toxicol. 2017, 120, 418-424. [CrossRef]

27. Snyder, S.M.; Low, R.M.; Stocks, J.C.; Eggett, D.L.; Parker, T.L. Juice, Pulp and Seeds Fractionated from Dry Climate Primocane Raspberry Cultivars (Rubus idaeus) Have Significantly Different Antioxidant Capacity, Anthocyanin Content and Color. Plant Foods Hum. Nutr. 2012, 67, 358-364. [CrossRef]

28. Chen, L.; Teng, H.; Xie, Z.L.; Cao, H.; Cheang, W.S.; Skalicka-Woniak, K.; Georgiev, M.I.; Xiao, J.B. Modifications of dietary fla-vonoids towards improved bioactivity: An update on structure-activity relationship. Crit. Rev. Food Sci. Nutr. 2018, 58, 513-527.

29. Boissonneault, G.A. Dietary fat, immunity and inflammatory disease. In Ching Kuang Chow, Fatty Acids in Foods and Their Health Implications, 3rd ed.; CRC Press: Boca Raton, FL, USA, 2007; pp. 777-807.

30. Vinayagam, R.; Xiao, J.; Xu, B. An insight into anti-diabetic properties of dietary phytochemicals. Phytochem. Rev. 2017, 16, 535-553. [CrossRef]

31. Fotschki, B.; Jurgonski, A.; Ju'skiewicz, J.; Zdunczyk, Z. Dietary supplementation with raspberry seed oil modulates liver func-tions, inflammatory state, and lipid metabolism in rats. J. Nutr. 2015, 145, 1793-1799. [CrossRef] [PubMed]

32. Teng, H.; Chen, L.; Huang, Q.; Wang, J.; Lin, Q.; Liu, M.; Lee, W.Y.; Song, H. Ultrasonic-Assisted Extraction of Raspberry Seed Oil and Evaluation of Its Physicochemical Properties, Fatty Acid Compositions and Antioxidant Activities. PLoS ONE 2016, 11, e0153457. [CrossRef] [PubMed]

33. Majewski, M.; Kucharczyk, E.; Kaliszan, R.; Markuszewski, M.; Fotschki, B.; Juśkiewicz, J.; Borkowska-Sztachańska, M.; Ognik, K. The Characterization of Ground Raspberry Seeds and the Physiological Response to Supplementation in Hypertensive and Normotensive Rats. Nutrients 2020, 12, 1630. [CrossRef] [PubMed]

34. Scientific Committee on Food, Commission of the European Communities. Reports of the Scientific Committee for Food: Nu-Trient and Energy Intakes for the European Community; Office for Official Publications of the European Communities: Luxembourg, 1993.

35. NIH. National Institutes of Health. Nutrient Recommendations: Dietary Reference Intakes (DRI). Available online: https: / / ods.od.nih.gov/HealthInformation/Dietary_Reference_Intakes.aspx (accessed on 26 April 2021).

36. Astrup, A.; Dyerberg, J.; Elwood, P.; Hermansen, K.; Hu, F.B.; Jakobsen, M.U.; Kok, F.J.; Krauss, R.M.; Lecerf, J.M.; Legrand, P.; et al. The role of reducing intakes of saturated fat in the prevention of cardiovascular disease: Where does the evidence stand in 2010? Am. J. Clin. Nutr. 2011, 93, 684-688. [CrossRef]

37. FAO/WHO. Interim Summary of Conclusions and Dietary Recommendations on Total Fat \& Fatty Acids, in Expert Consulta-tion on Fats and Fatty Acids in Human Nutrition. Jt. FAO/WHO Expert Consult. Fats Fat. Acids Hum. Nutr. 2008, 16, 10-14.

38. Traber, M.G. Vitamin E Regulatory Mechanisms. Annu. Rev. Nutr. 2007, 27, 347-362. [CrossRef]

39. Sen, C.K.; Khanna, S.; Roy, S. Tocotrienols: Vitamin E beyond tocopherols. Life Sci. 2006, 78, 2088-2098. [CrossRef] [PubMed]

40. Brown, B.G.; Crowley, J. Is there any hope for vitamin E? JAMA 2005, 293, 1387-1390. [CrossRef] [PubMed]

41. Schagen, S.K.; Zampeli, V.A.; Makrantonaki, E.; Zouboulis, C.C. Discovering the link between nutrition and skin aging. DermatoEndocrinology 2012, 4, 298-307. [CrossRef] [PubMed]

42. Boelsma, E.; Hendriks, H.F.; Roza, L. Nutritional skin care: Health effects of micronutrients and fatty acids. Am. J. Clin. Nutr. 2001, 73, 853-864. [CrossRef] [PubMed]

43. Alaluf, S.; Heinrich, U.; Stahl, W.; Tronnier, H.; Wiseman, S. Dietary Carotenoids Contribute to Normal Human Skin Color and UV Photosensitivity. J. Nutr. 2002, 132, 399-403. [CrossRef] [PubMed]

44. Ryan, A.S.; Goldsmith, L.A. Nutrition and the skin. Clin. Dermatol. 1996, 14, 389-406. [CrossRef]

45. Gašperlin, M.; Gosenca, M. Main approaches for delivering antioxidant vitamins through the skin to prevent skin ageing. Expert Opin. Drug Deliv. 2011, 8, 905-919. [CrossRef] [PubMed]

46. Lee, J.; Jiang, S.; Levine, N.; Watson, R.R. Carotenoid supplementation reduces erythema in human skin after simulated solar radiation exposure. Proc. Soc. Exp. Biol. Med. 2000, 223, 170-174. [CrossRef] [PubMed]

47. Chang, C.; Liu, B.; Bao, Y.; Tao, Y.; Liu, W. Efficient bioconversion of raspberry ketone in Escherichia coli using fatty acids feedstocks. Microb. Cell Factories 2021, 20,1-12. [CrossRef]

48. Velicanski, A.; Cvetkovic, D.; Markov, S. Screening of antibacterial activity of raspberry (Rubus idaeus L.) fruit and pomace extracts. Acta Period. Technol. 2012, 43, 305-313. [CrossRef]

49. Ácsová, A.; Hojerová, J.; Janotková, L.; Bendova, H.; Jedlickova, L.; Hamranova, V.; Martiniakova, S. The real UVB photoprotective efficacy of vegetable oils: In vitro and in vivo studies. Photochem. Photobiol. Sci. 2021, 20, 139-151. [CrossRef] [PubMed] 
50. Fosman, J.; Fosman, U. Raspberry Seed Oil-Sunscreen or not? Nyponros. 2017. Available online: https://nyponros.com/en/ sunscreen/rasberryseed-oil-sunscreen (accessed on 24 April 2021).

51. Kafkas, E.; Özgen, M.; Özoğul, Y.; Türemiş, N. Phytochemical and fatty acid profile of selected red raspberry cultivars: A com-parative study. J. Food Qual. 2008, 31, 67-78. [CrossRef]

52. World Intellectual Property Organization (WIPO). Available online: https://patentscope.wipo.int/search/en/search.jsf (accessed on 24 April 2021). 